\title{
Effects of autoclaving and high pressure on allergenicity of hazelnut proteins
}

\author{
Elena López ${ }^{1 *}$, Carmen Cuadrado², Carmen Burbano ${ }^{2}$, Maria Aranzazu Jiménez ${ }^{3}$, Julia Rodríguez ${ }^{1}$ \\ and Jesús F Crespo ${ }^{1}$
}

\begin{abstract}
Background: Hazelnut is reported as a causative agent of allergic reactions. However it is also an edible nut with health benefits. The allergenic characteristics of hazelnut-samples after autoclaving (AC) and high-pressure (HHP) processing have been studied and are also presented here. Previous studies demonstrated that AC treatments were responsible for structural transformation of protein structure motifs. Thus, structural analyses of allergen proteins from hazelnut were carried out to observe what is occurring in relation to the specific-lgE recognition of the related allergenic proteins. The aims of this work are to evaluate the effect of AC and HHP processing on hazelnut in vitro allergenicity using human-sera and to analyse the complexity of hazelnut allergen-protein structures.
\end{abstract}

Methods: Hazelnut-samples were subjected to AC and HHP processing. The specific lgE- reactivity was studied in 15 allergic clinic-patients via western blotting analyses. A series of homology-based-bioinformatics 3D-models (Cora 1, Cora 8, Cora 9 and Cora 11) were generated for the antigens included in the study to analyse the co mplexity of their protein structure. This study is supported by the Declaration of Helsinki and subsequent ethical guidelines.

Results: A severe reduction in vitro in allergenicity to hazelnut after AC processing was observed in the allergic clinicpatients studied. The specific-lgE binding of some of the described immunoreactive hazelnut protein-bands: Cora 1 $\sim 18 \mathrm{KDa}$, Cora $8 \sim 9 \mathrm{KDa}$, Cora $9 \sim 35-40 \mathrm{KDa}$ and Cora $11 \sim 47-48 \mathrm{KDa}$ decreases. Furthermore a relevant glycosylation was assigned and visualized via structural analysis of proteins (3D-modelling) for the first time in the protein-allergen Cora 11 showing a new role which could open a new door for allergenicity-unravellings.

Conclusion: Hazelnut allergenicity-studies in vivo via Prick-Prick and other means using AC processing are crucial to verify the data we observed via in vitro analyses. Glycosylation studies provided us with clues to elucidate, in the near future, mechanisms of the structures that contribute to hazelnut allergenicity, which thus, in turn, help alleviate food allergens.

Keywords: Structural analysis of allergen-proteins and Glycosylation

\section{Introduction}

Food allergies are receiving more attention and seem to be increasing, especially in Western countries [1-5]. Consumers are becoming more aware and are more informed about food sensitivities, including allergies. Allergies to hazelnuts, tend to be of a more severe nature, causing life-threatening and sometimes fatal reactions. Indeed, symptoms upon hazelnut- ingestion are often confined to the mouth and throat, but severe systemic

\footnotetext{
* Correspondence: elena.lopez.villar@gmail.com

${ }^{1}$ Centro de Investigación ( $\left.i+12\right)$ del Hospital Universitario 12 de Octubre, Avda de Córdoba, s/n, 28041, Madrid, Spain

Full list of author information is available at the end of the article
}

reactions have been described in some patients [6-14]. Also, hazelnut is a good habit in a healthy nutritional regimen. Type I food allergy is defined as an IgEmediated response to a protein (or proteins) in a food source. It is not known why a food protein that is innocuous and well-tolerated by most individuals, triggers an allergic response in sensitive individuals [15-17].

The portion of the food protein recognized by IgE is called the epitope. Epitopes are generally categorized as linear or conformational, where linear epitope involves a contiguous stretch of amino acids, and a conformational epitope involves non contiguous amino acids which form a three-dimensional/structural motif. Individual

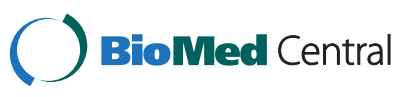


patients may differ significantly in their sensitivity toward an allergen; however, the basis of such differential sensitivities remains to be elucidated $[17,18]$.

Moreover, studies of protein thermal conformational stability under different treatments from both biochemical and techno functional points of view need to be extended $[19,20]$. In addition, it has been suggested that modifications in allergenicity caused by thermal treatments could provide a better understanding of the risk of introducing hazelnuts into human daily food intake. Furthermore Hansen et al., [21] indicated that roasting of hazelnuts reduces the allergenicity. Also, Ortolani et al., [22] selected subjects with a history of allergic reactions on ingestion of hazelnut and determined how many had true allergy by means of the double-blind, placebocontrolled food challenge (DBPCFC), showing that $78 \%$ of the analyzed subjects had a positive DBPCFC result.

In fact, allergy to hazelnuts has been frequently reported, but data on the identification and characterization of the hazelnut allergens, as well as on the reliability of the methods for in vitro and in vivo detection of specific IgE for these allergens, are scarce. In addition, different researches have indicated that post-translational modifications (PTMs) like phosphorylation and glycosylation can play a relevant role in allergenicity related to edible nuts including hazelnuts [23]. On the other hand, sequence and structural information improve the prediction of allergenic peptides. Motifs can also be mapped onto the 3Dstructure of a protein to identify epitopes and conserved functional areas [24]. Combining sequence analysis with structural representations can answer many questions about the nature of the IgE epitopes of allergens [25]. While single amino acid differences may be quite important in individual reactivity, a $3 \mathrm{D}$ view of the identified IgE binding sites can provide missing information about the possible relationships between structure and sequence [26].

We selected the hazelnut as an edible nut for its health benefits which makes the hazelnut food processing industry one of significant economic impact and profit [27-29]. The present study was specifically designed to evaluate the effects of $\mathrm{AC}$ and $\mathrm{HHP}$ processing on the allergenic characteristics of proteins from hazelnuts. This study aimed to combine functional research protein-allergen analysis via western blotting and structural analysis of allergen proteins from the hazelnut, in order to observe what is occurring in relation to the specific recognition of the allergenic proteins from hazelnuts by IgE using sera from patients allergic to hazelnuts with clinical significance. In addition, and in order to analyze the complexity level of the structural arrangements of the studied allergens, a bioinformatics study was done, generating 3D structural models for all of them looking for putative glycosylation motifs. As a general result, in all cases the structural complexity of the modelled proteins could act as a molecular explanation for the effects observed after AC treatment. As was previously demonstrated [30], AC treatment significantly modifies the proportion of secondary structural elements in proteins, being thus putatively responsible for their changes in allergenicity.

\section{Materials and methods}

\section{Statement of ethical approval}

This study was conducted in compliance with the international "Declaration of Helsinki." An informed consent about the procedures as well as permission from the Ethical Committee of 12 de Octubre and Carlos III Hospitals of Health was obtained (http://www.madrid.org/cs/Satelite? pagename=Hospital12Octure/Page/H12O_ home, http:// www.madrid.org/cs/Satellite?pagename=HospialCarlosIII).

This study adhered to the tenets of the Declaration of Helsinki. (http://www.wma.net/e/policy/b3.htm). (Declaration of Helsinki (1964), Belmont (1978) and agreement of Oviedo (1997) - the basic principles for human and biological samples research studies -) (http://www.isciii.es/htdocs/index. jsp). ("Working link": http://www.madrid.org/cs/Satelite? pagename $=$ Hospital12Octure/Page/H12O_home).

\section{Plant material, AC and HHP processing}

Raw and processed seeds were milled to pass through a $1 \mathrm{~mm}$ sieve (Tecator, Cyclotec 1093, Hoganas, Sweden), and the resulting meal was defatted with n-hexane ( $34 \mathrm{~mL} / \mathrm{g}$ of flour) for $4 \mathrm{~h}$, shaken, and air-dried after filtration of the n-hexane. Defatted flour was extracted twice in a solution of Sodium borate, $\mathrm{pH} 8.0$, plus $0.5 \mathrm{M}$ $\mathrm{NaCl}$ at a $1: 10 \mathrm{w} / \mathrm{v}$ ratio for $1 \mathrm{~h}$ at $4^{\circ} \mathrm{C}$ by stirring. The extract was clarified by centrifugation at $27000 \mathrm{~g}$ for $20 \mathrm{~min}$ at $4^{\circ} \mathrm{C}$, and the supernatants were dialyzed against $\mathrm{H} 2 \mathrm{O}$ for $48 \mathrm{~h}$ at $4^{\circ} \mathrm{C}$ using a dialysis membrane with a cut-off of $3.5 \mathrm{kDa}$ and freeze-dried. The protein content of each sample was measured according to the Leco dye-binding assay (Bio-Rad, Hercules, CA) using bovine serum albumin (BSA; Sigma, St. Louis, MO) as a standard. Defatted hazelnut flour samples (30 g) were hydrolyzed (water $1: 4 \mathrm{w} / \mathrm{v}$, for $20 \mathrm{~h}$, at $4^{\circ} \mathrm{C}$ ). The obtained solutions were subjected to centrifugation (1200 rpm, $10 \mathrm{~min}$.) and different processing of AC and HHP were applied. The resulting pellets and supernatants were frozen and stored at $-20^{\circ} \mathrm{C}$. The $\mathrm{AC}$ and $\mathrm{HHP}$ processing applied were: $121^{\circ} \mathrm{C} 15 \mathrm{~min} ., 121^{\circ} \mathrm{C} 30 \mathrm{~min}$., $138^{\circ} \mathrm{C} 15 \mathrm{~min} ., 138^{\circ} \mathrm{C} 30 \mathrm{~min}$. and $300 \mathrm{Mba}, 400 \mathrm{Mba}$, $500 \mathrm{Mba}$ and $600 \mathrm{Mba}$, respectively. All the processed hazelnut flour samples were centrifuged and frozen in order to obtain the lyophilized ones to be analyzed. (Note: Mba: units Milibar pressure, AC: Autoclave heat process, HHP: high pressure process). 


\section{SDS-PAGE gel and immunoblotting analyses}

Denaturing protein and SDS-PAGE gel were performed essentially according to the method of Fling and Gregerson [31]. Samples (10 g per well) were mixed 5:1 with loading buffer (8\% SDS, 8 mM EDTA, 40\% glycerol, $1 \mathrm{M}$ -mercaptoethanol (-ME), and $0.01 \%$ bromophenol blue in $0.25 \mathrm{M}$ Tris- $\mathrm{HCl}, \mathrm{pH} 7.5)$ heated at $100^{\circ} \mathrm{C}$ for $10 \mathrm{~min}$, electrophoresis in 4-20\% gradient analytical SDS-polyacrylamide gels employing a Mini-Protean III apparatus (Bio- Rad), and either stained with Coomassie Brilliant Blue R-250 or transferred to poly (vinylidene difluoride) (PVDF) membranes (Bio -Rad). For immunoblot, proteins $(25 \mu \mathrm{g})$ were electrophoretically transferred from the gels to PVDF by applying a constant current of $250 \mathrm{~mA}$ during $1.30 \mathrm{~h}$ at room temperature, essentially according to the method of Towbin et al. [32]. The membranes were stained with red-ponceau to verify protein transfer. Western immunoblotting using pooled human sera was done, as described later, with the necessary modifications to optimize the hazelnut sample analysis for this study [33]. Blots were blocked in phosphate-buffered saline plus $0.1 \%$ Tween 20 containing $1 \%$ fat-free milk powder for $2 \mathrm{~h}$ at room temperature and then incubated overnight at room temperature with individual and pooled sera (1:5 dilution). For individual serum and also for the pool of sera, a mouse anti-human IgE mAb HE-2 ascitic fluid was used as first antibody (diluted 1:4000 in blocking buffer) for $1 \mathrm{~h}$ at room temperature (RT). After 4 washing steps (10 mins each one with phosphate-buffered saline plus $0.1 \%$ Tween 20 ), a goat anti-mouse IgG peroxidise- conjugated antibody was used as second antibody (diluted 1:5000 in $1 / 2 \mathrm{v} / \mathrm{v}$ in blocking solution) for $1 \mathrm{~h}$ at RT. Finally, immunoreactive bands were visualized using the ECL chemiluminiscent kit (Bio-Rad). Coomassie-stained gels and immunostained membranes were scanned using a HPS scanjet 5590P densitometer. The files generated were analyzed with Quantity One software (Bio-Rad) using the precision plus protein standard TM (Biorad) prestained SDS-PAGE protein mixture (Bio-Rad) as standard.

\section{Immuno-CAP-FEIA allergy blood test}

For the CAP (fluorenzymeimmunoassay CAP Pharmacia Diagnostic, Uppsala, Sweden) tests, each serum was incubated with the same volume of progressive dilutions $(0.001-1 \mathrm{mg} / \mathrm{mL})$ of each inhibitor protein solution in PBS buffer for $14 \mathrm{~h}$ at $4^{\circ} \mathrm{C}$ with agitation. After incubation, the samples were centrifuged, hazelnut commercial Immuno-CAP was then added, and specific IgE levels were assessed, according to the CAP System procedure (Pharmacia Diagnostic, Uppsala, Sweden). BSA was used as negative control. The assay was performed in duplicate samples, and each one was tested in duplicate [34-36].

\section{Patients}

Fifteen patients (from num.3 until num.17- Figure $1 \mathrm{~A}$, $\mathrm{B}, \mathrm{C})$ with detectable hazelnut- specific IgE as quantified by the CAP-FEIA assay ( $>0.35$ kilounits/L) (Pharmacia Diagnostic, Uppsala, Sweden) (Table 1), were use to evaluate the reduction in allergenicity by thermal treatment of hazelnut. The fifteen patients were selected as they belong to hazelnut-allergic patients without allergy to another edible nut.

In addition, patient num. 1 and patient num. 2 -Figure 1 A- were used as negative controls - with negative specific IgE recognition to hazelnuts and quantified by using the (CAP-FEIA assay $(<0.35$ kilounits/L, Pharmacia Diagnostic, Uppsala, Sweden). The negative controls were selected as they belong to healthy patients without allergy to edible nuts in order to focus the data in allergen-hazelnut recognised protein-bands from human IgE hazelnut- allergic patients.

\section{Structural analysis and modelling procedures of hazelnut proteins Cor_a_1.04, Cor_a_8, Cor_a_9 and Cor_a_11} 3D models of hazelnut alergens Cor_a_1.04 (Uniprot codes: Q9FPK2, Q9FPK3, Q9FPK4 and Q9SWR4), Cor_a_8 (Uniprot code: Q9ATH2), Cor_a_9 (Uniprot code: Q8W1C2) and Cor_a_11 (Uniprot code: Q8S4P9) were generated using homology modelling procedures and the coordinates of the following Protein Data Bank structures as templates:

Cor_a_1.04. Template: Crystal structure of major pollen allergen Bet v 1d/h from Betula pendula. Protein Data Bank code: 3 K78 [37]. Blast E-value: 6.1x10 - 55 . Sequence Identity: 66\%

Cor_a_8. Template: Crystal structure of Pru p3, nonspecific lipid transfer protein from Prunus persica. Protein Data Bank code: 2ALG_A [38]. Blast E-value: $1.3 \times 10$ - 29. Sequence Identity: 59\%

Cor_a_9. Template: Crystal structure of the hexameric form of Pru du amandin from Prunus dulcis. Protein Data Bank code: 3EHK [39]. Blast E-value: 1.4x10 - 146. Sequence Identity: $56 \%$

Cor_a_11. Template: Crystal structure of soybean beta-conglycinin beta homotrimer. Protein Data bank code: 1IPK [40]. Blast E-value: 2.0x10 - 63. Sequence Identity: $354 \%$

Models were built using the SWISS-MODEL server [41-43] available at http://swissmodel.expasy.org//SWISSMODEL.html, and their structural quality was checked using the analysis programmes provided by the same server (Anolea/Gromos). Global model quality estimation scores QMEAN4 [44] were: Cor_a_1.04: 0.741, Cor_a_8: 0.671, Cor_a_9: 0.548 and Cor_a_11: 0.608, that are within the range of those accepted for homology-based structure 

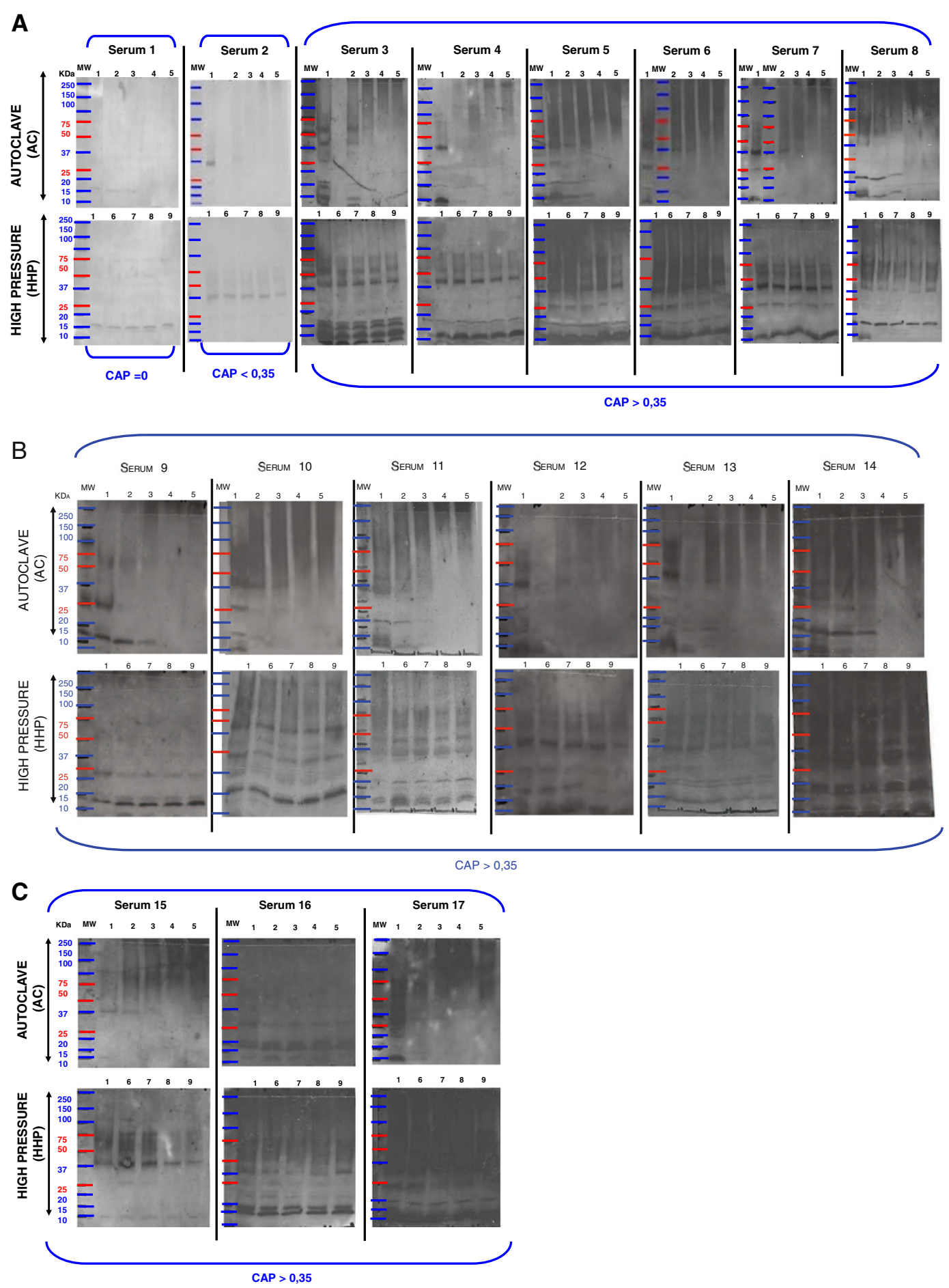

Figure 1 Western blotting analysis of hazelnut processed by AC and HHP treatments. Western blotting analysis of AC/HHP flour hazelnut samples incubated with clinical sera from patients allergic to hazelnut (*) Figure 2 is illustrated in 3 sections (A), (B) and (C) in order to visualize 34 western blots in a proper way. Number 1 corresponds to raw hazelnut flour; numbers 2, 3, 4 and 5 correspond to $\mathrm{AC} 121^{\circ} \mathrm{C} 15$ mins., $121^{\circ} \mathrm{C} 30$ mins., $138^{\circ} \mathrm{C} 15$ mins., and $138^{\circ} \mathrm{C} 30$ mins., respectively. Numbers 6, 7, 8 and 9 correspond to HHP 300Mba, 400Mba, 500Mba and 600Mba respectively. Sera 1 and 2 correspond to non allergic patients to hazelnut (negative controls). (Note: (i) The film-exposition - after the ECL incubation- took longer than $24 \mathrm{~h}$ to visualize the bands of the negative controls: sera 1 and 2) (ii) The film-exposition - after the ECL incubationtook between $5 \mathrm{~s}$ and $1 \mathrm{~min}$. according to the different sera tested in order to visualize the bands: from serum 3 until 17) (MW: molecular weight, AC: autoclave process, HHP: high pressure process, KDa: kilodalton). 
Table 1 Illustration of clinic symptoms of patients allergic to hazelnut

\begin{tabular}{|c|c|c|c|c|}
\hline Patient & Age & Sex & Reported symptoms & CAP \\
\hline$\# 1$ & 57 & $\mathrm{~F}$ & & 0 \\
\hline$\# 2$ & 33 & $\mathrm{~F}$ & & $<0.35$ \\
\hline$\# 3$ & 26 & M & Oral allergy syndrome & 2.68 \\
\hline$\# 4$ & 33 & $\mathrm{~F}$ & Acute urticaria & 2.5 \\
\hline \# 5 & 16 & $\mathrm{~F}$ & Avoidance & 2.97 \\
\hline \# 6 & 28 & $\mathrm{~F}$ & Oral allergy syndrome & 4.03 \\
\hline$\# 7$ & 16 & $\mathrm{~F}$ & Oral allergy syndrome & 2.08 \\
\hline$\# 8$ & 21 & M & Systemic anaphylaxis & 4.6 \\
\hline$\# 9$ & 26 & $\mathrm{~F}$ & $\begin{array}{l}\text { Rhinoconjunctivitis, } \\
\text { angioedema, oral allergy } \\
\text { syndrome }\end{array}$ & 0.58 \\
\hline \# 10 & 27 & $\mathrm{~F}$ & Systemic anaphylaxis & 1.92 \\
\hline \# 11 & 30 & M & Oral allergy syndrome & 2.42 \\
\hline \# 12 & 42 & $\mathrm{~F}$ & Oral allergy syndrome & 1.9 \\
\hline \# 13 & 28 & M & Avoidance & 0.87 \\
\hline \# 14 & 57 & $\mathrm{~F}$ & Oral allergy syndrome & 2.5 \\
\hline \# 15 & 47 & M & Oral allergy syndrome & 4.13 \\
\hline \# 16 & 30 & $\mathrm{~F}$ & Avoidance & 0.42 \\
\hline \# 17 & 49 & M & Avoidance & 0.47 \\
\hline
\end{tabular}

Patients allergic to hazelnut proteins showed clinic symptoms from oral allergy syndrome, acute urticaria, systemic anaphylaxis, rhinoconjunctivitis, angioedema to avoidance (avoidance: advised to avoid hazelnut food because of a positive skin test). The resulting data including the age and sex, are illustrated in this table. (Note: F: female, M: male).

Avoidance*: advised to avoid the food because of a positive skin test, without a clinical history of hazelnut allergy.

models. To optimize geometries, models were energy minimized using the GROMOS $43 \mathrm{~B} 1$ force field implemented in DeepView [45,46], using 500 steps of steepest descent minimization followed by 500 steps of conjugategradient minimization.

Figures were generated using the Pymol Molecular Graphics System (Schrödinger, LLC). [SWISSPROT database http://expasy.org/sprot/].

\section{Results}

\section{SDS-PAGE gel and immunoblotting analyses}

(a) The allergenicity was analyzed by IgEimmunoblotting. In the case of the raw- hazelnut flour (positive control), IgE antibodies from 15 individual sera allergic to hazelnut recognized bands at (a) $9 \mathrm{KDa}$ bands which correlate with Cor_a_8 protein -non-specific lipid transfer proteins family (nsLTPs), (b) 18 KDa bands which belongs to Cor_a_1.04 protein -Bet v1 family-, (c) 35-40 KDa bands which belong to Cor_a_9 protein $-11 \mathrm{~S}$ seed storage globulin, cupin family- and (d) $\sim 47-48 \mathrm{KDa}$ bands which belong to Cor_a_11 protein -Vicilin family-. A severe reduction in allergenicity to hazelnut flour in vitro after autoclaving at $121^{\circ} \mathrm{C} 15$ mins., $121^{\circ} \mathrm{C} 30$ mins., $138^{\circ} \mathrm{C} 15$ mins and $138^{\circ} \mathrm{C} 30$ mins, was observed in the allergic clinic patients with a CAP value $>0.35$ kilounits/L by western blotting analysis. No reduction in allergenicity in vitro after HHP treatments was observed in any serum of the 15 patients, which were also analyzed by immunoblotting when using the same conditions for all the sera analyses [31-33].

(b) Autoclaving $121^{\circ} \mathrm{C} 15$ mins and $121^{\circ} \mathrm{C} 30$ mins hazelnut flour samples, which were analyzed by western blotting showed that, mainly the IgE binding of some of the described immunoreactive hazelnut protein-bands (Cor_a_1 18KDa, Cor_a_8 $\sim 9 \mathrm{KDa}$-, Cor_a_9 35-40KDa) decreases. This occurred in the majority of sera tested. Autoclaving treatments $138^{\circ} \mathrm{C} 15$ mins and $138^{\circ} \mathrm{C} 30$ mins of hazelnut flour samples, which were analyzed by western blotting, showed that the IgE binding of all of the described immunoreactive hazelnut proteinbands (Cor_a_1 18 KDa, Cor_a_8 9 KDa-, Cor_a_9 35-40 KDa, Cor_a_11 47-48 KDa) disappear. This occurred in all the sera tested (15 western blotting analyses from 15 clinical sera of 15 patients diagnosed with actual allergy to hazelnuts). [Molecular weights (MW) and allergen names are described in Database Food Allergies and Swissprot Database - ExPaSy Proteomic Server respectively; http://foodallergens.ifr.ac.uk/default.html, http:// www.uniprot.org/uniprot/, http://expasy.org/sprot/].

(c) All protein bands from Coomassie-stained gel and immunostained membranes were scanned using a HPS scanjet 5590P densitometer. The files generated were analyzed with Quantity One software (BioRad), which allowed us to visualize the severe reduction in allergenicity in vitro via the decrease of intensity of the protein-bands when comparing the raw-hazelnut flour (positive control: 100\% intensity) with the autoclaved samples: $121^{\circ} \mathrm{C} 15$ mins., $121^{\circ} \mathrm{C}$ 30 mins., $138^{\circ} \mathrm{C} 15$ mins and $138^{\circ} \mathrm{C} 30$ mins. Indeed, severe allergenicity reduction in vitro was ensured via $\mathrm{p} \leq 0.05$ value obtained via Quantity One software and excel for all studied patients.

(d)When loading $\sim 25 \mu \mathrm{g}$ of soluble proteins in loading buffer, the raw hazelnut flour does not show a different protein pattern compared to the processed ones by HHP treatments (from Sera 3 to 17) (downpanel HHP Figure 1 A, B, C). Nevertheless, the raw hazelnut flour shows a different protein pattern compared to that processed by AC treatments. Strongest conditions of the $\mathrm{AC}$ treatment decrease the IgE binding of allergenic hazelnut proteins (from Sera 3 to 17). In the case of the analysis of the 


\section{A}
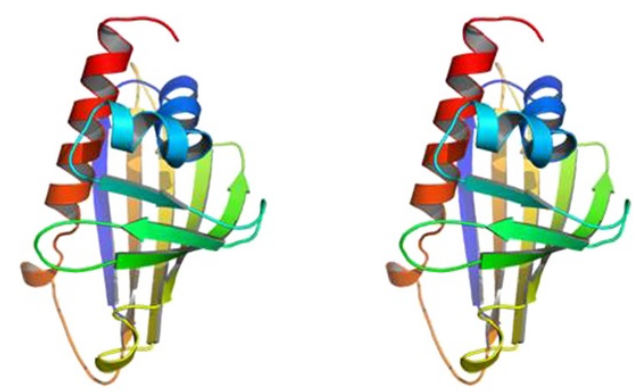

Cor_a_10.4_Q9FPK2

Cor_a_10.4_Q9FPK3
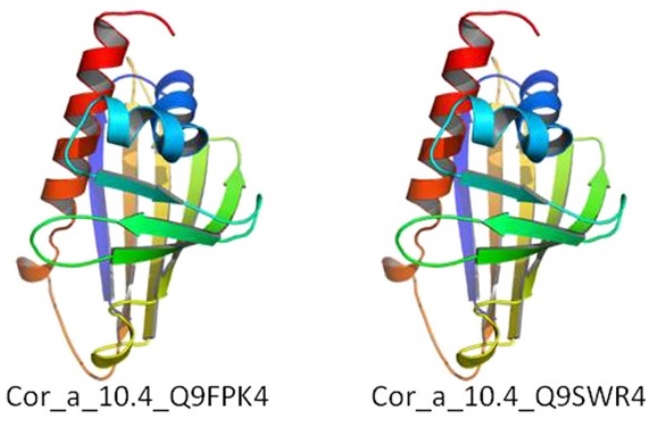

Cor_a_10.4

B

\begin{tabular}{|c|c|c|c|c|c|c|}
\hline PK2 & 1 & MGVFSYED & EATSVIPPAP & LFKSFVLDAD & NL IPKVAPQH & FTS. \\
\hline Q9FPK3 & 1 & MGVFCYED & EATSVIPPAF & LFKSFVLDAD & NL IPKVAPQH & FTGAENLEGN \\
\hline Q9FPK4 & 1 & MGVFSYED & EATSVIPPAF & LFKSFVLDAD & NL IPKVAPQH & FTGAENLEGN \\
\hline Q9SWR4 & 1 & MGVFCYED & EATSVIPPAF & LFKSFVLDAD & NL IPKV APQH & FTSAENLEGN \\
\hline $3 \mathrm{~K} 78$ & 3 & vfnyei & ettsvipaar & lfkafildgd & nlvpkvapqa & issveniegn \\
\hline Cor_a_10 & & sssss & ssss & hhhhhh & hhhhhh & sssss \\
\hline $3 \mathrm{~K} 7 \overline{8} \_\bar{s} S$ & & ssses & ssss & hhhhhh & hhhhhh & sss \\
\hline FPK2 & 49 & GPGTIKKIT & FAEGNEFKYI & KHKVEE IDHA & NFKYCYSIIE & GGPLGHTLEK \\
\hline Q9FPK3 & 49 & GPGTIKKIT & FAEGSEFKYI & 1 KHKVEE IDHA & NFKYCYSIIE & GGPLGHTLEK \\
\hline Q9FPK4 & 49 & GPGTIKKIT & FAEGSEFKYY & KHKVEEIDHA & NFKYCYSIIE & GGPLGHTLEK \\
\hline Q9SWR4 & 49 & GGPGTIKKIT & FAEGNEF KYI & 1 KHKVEEIDHA & NFKYCYSIIE & GGPLGHTLEK \\
\hline $3 \mathrm{~K} 78$ & 49 & gpgtikkin & fpegfpfky & kdrvdevdht & nfkynysvie & ggpvgdt lek \\
\hline Cor_a_t & & sss & sss & sss & ssssssss & hhhssss \\
\hline $3 \mathrm{k} 7 \overline{8} \_\overline{\mathrm{s}} \mathrm{S}$ & & ssssss & sss & ssssssss & ssssssss & $\mathrm{hhh}$ \\
\hline FPK2 & 99 & PYE IKMAAA & PHGGGSILK & TSK & SINEEEIKAG & KEKAAGLFKA \\
\hline Q9FPK3 & 99 & SYE IKMAAA & PHGGGSILK & TSKYHTKGNA & SISEEEIKAG & KEKAAGLFKA \\
\hline Q9FPK4 & 99 & SYEIKMAAA & PHGGGSILK & TSKYHTKGNA & SISEEEIKAG & KEKAAGLFKA \\
\hline Q9SWR4 & 99 & ISYEIKMAAA & PHGGGSILK & TSKYHTKGNA & SINEEEIKAG & KEKAAGLFKA \\
\hline $3 \mathrm{~K} 78$ & 99 & isneikivat & pdgg-cvlk & snkyhtkgnh & evkaeqvkas & kemget $11 \mathrm{ra}$ \\
\hline Cor_a_10 & & sssssssa & ss: & & $\mathrm{hh}$ & hhhhhhhhhh \\
\hline $3 \mathrm{~K} 78$ - 55 & & ssssssssss & $s$ ss: & sss & $\mathrm{hh}$ & hhnhhnhhhh \\
\hline Q9FP & 149 & D & $\mathrm{AYC}$ & & & \\
\hline Q9FF & 149 & EAY & $\mathrm{T}$ & & & \\
\hline Q9FPI & 149 & EAYL & TYC & & & \\
\hline Q9SWR4 & 149 & VEAYLLAHPD & $\mathrm{BYC}$ & & & \\
\hline $3 \mathrm{~K} 78$ & 148 & vesyllahsd & & & & \\
\hline & & & & & & \\
\hline K & & hhhhhh & & & & \\
\hline
\end{tabular}

Cor_a_10.4

Figure 2 (See legend on next page.) 
(See figure on previous page.)

Figure 2 3D structure models for Cor_a_1.04 proteins. (A). 3D models for the four Cor_a_1.04 proteins (Uniprot codes: Q9FPK2, Q9FPK3, Q9FPK4 and Q9SWR4). Models are coloured from N-ter (blue) to C-ter (red) ends. (B). Structure alignment of the four Cor_a_1.04 proteins identified by their Uniprot codes, and the crystal structure of major pollen allergen Bet $\vee 1 \mathrm{~d} / \mathrm{h}$ from Betula pendula (PDB code: 3 K78; [35]). Secondary structure elements of both the model and template are included. Differences among the sequences of the four Cor_a_1.04 proteins are indicated in red.

Serum $1(C A P=0)$ a band slightly higher than 15 $\mathrm{KDa}$ is observed in the lanes of the raw flour, $121^{\circ} \mathrm{C}$ 15 mins., and $121^{\circ} \mathrm{C} 30$ mins. Nevertheless, this protein-band $(>15 \mathrm{KDa})$ disappears in the lanes of the $138^{\circ} \mathrm{C} 15$ mins., and $138^{\circ} \mathrm{C} 30$ mins. In the case of the analysis of the Serum 2 (CAP $<0,35)$ : (i) The raw hazelnut flour does not show a different protein pattern compared to that processed by HHP treatments (down- panel HHP Figure 1). (ii) The raw hazelnut flour shows a different protein pattern compared to that processed by AC treatments. Strongest conditions of the AC treatment decrease the IgE binding of allergenic hazelnut proteins. (uppanel AC Figure 1 A, B, C).

(e) In addition, other negative control (as internal control, intra-assay) which was also used, is the incubation of raw hazelnut flour with the first and secondary antibodies (a mouse anti-human IgE mAb HE-2 ascitic fluid and a goat anti-mouse IgG peroxidise- conjugated antibody) respectively. In the lane of the negative control protein-bands were not visualized as a good evaluation.

\section{CAP-FEIA of patients allergic to hazelnuts}

Patients allergic to hazelnut proteins were selected for this research study.

Fifteen patients showed clinic symptoms including oral allergy syndrome, acute urticaria, systemic anaphylaxis, rhinoconjunctivitis, angioedema and avoidance (avoidance: advised to avoid hazelnut food because of a positive skin test).

The resulting data including the age and sex, are illustrated in the Table 1.

\section{Structural analysis Modelling procedures of hazelnut proteins Cor_a_1.04, Cor_a_8, Cor_a_9 and Cor_a_11} 3D structural models were generated for the allergenic hazelnut antigens of this study:

Cor_a_1.04, Cor_a_8, Cor_a_9 and Cor_a_11 proteins. In the four cases, the structure of close homologue proteins were already available in the Protein Data Bank as crystallized structures, allowing the generation of good quality models. Cor_a_1.04 antigen is represented by four individual, closely related, proteins (Uniprot database codes: Q9FPK2, Q9FPK3, Q9FPK4 and Q9SWR4). Models for the four Cor_a_1.04 proteins were constructed using as template the crystal structure of the close relative major pollen allergen Bet $\mathrm{v} 1 \mathrm{~d} / \mathrm{h}$ from Betula pendula (PDB code: 3 K78; [37]). Due to the very similar sequence of the four proteins (Figure 2B), the generated 3D models were nearly identical (Figure 2A), exhibiting a complex alpha + beta scaffolding.

Model for the soluble domain of Cor_a_8 protein, after signal peptide processing, was built according to the 3D structure of the crystal structure of Pru p3, non-specific lipid transfer protein from Prunus persica (PDB code: 2ALG_A; [38]). Figure 3A shows the structure of the obtained model, enriched in alpha helix elements located in close contact to two lipid molecules, as predicted according to its sequence similarity to the template (Figure 3B).

In the case of Cor_a_9 allergen, a extremely complex, beta sheet-enriched, structure is predicted composed of six monomers arranged in two trimeric structures positioned in a base-to-base dimeric assembly (Figure 4A-B), as deduced by the close sequence similarity to the crystal structure of Pru du amandin from Prunus dulcis (PDB code: 3EHK; [39]), as shown in Figure 4C. Some protein segments, probably forming mobile non-structured loops, were not included in the model (Figure $4 \mathrm{C}$, residues coloured in red) due to the lack of an adequate structural template, as their counterparts are also missing in the original crystal structure.

Similarly to Cor_a_9, Cor_a_11 antigen was also modelled as a trimeric structure, formed by three beta sheet-enriched monomers (Figure 5A-B). Modelled spatial arrangement is equivalent to that exhibited by the selected template, the crystal structure of soybean beta- conglycinin beta protein (PDB code: 1IPK; [40]) based on their sequence similarity (Figure 5D). It has been reported that Cor_a_11 was glycosylated in residue Asn301 via MALDITOF (matrix-assisted laser-desorption ionization-time-offlight) MS mode analyses [41]. Position of a molecule of Nacetyl-D-glucosamine (NAG) was also modelled bound to Asn301, a residue located in a very structured, beta sheetenriched domain. As shown -for the first time- in Figure $5 \mathrm{C}$, glycosylated residue is positioned on the surface of the protein, additionally validating the model.

The obtained structural models of the four studied allergenic proteins indicated in all cases that a highly complex arrangement is present in all cases, including both alpha and beta secondary elements as well 

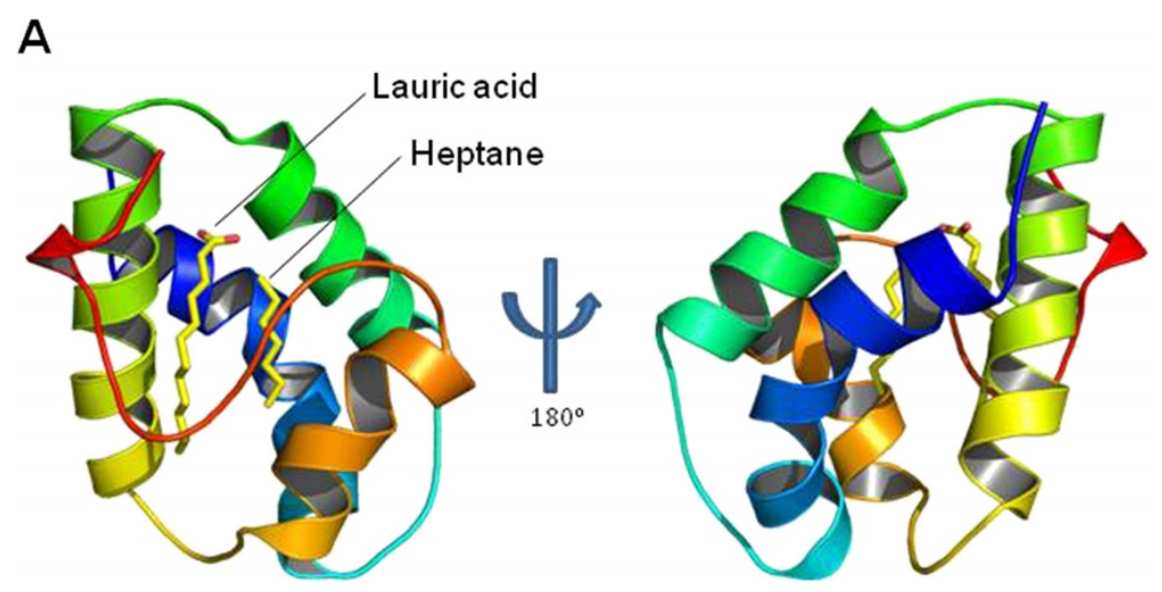

$\mathbf{B}$

\begin{tabular}{|c|c|c|c|c|c|c|}
\hline & & signal pept & ide & & & \\
\hline Cor_a_e & 1 & MGSLKLVC & AVLLCMIVA. & PVBRASLTCP & QIKGNLTPCV & LYLKNGGVLP \\
\hline $2 \mathrm{AL} \overline{\mathrm{G}}$ & 1 & & & mitcg & qvssslapei & pyvrgggavp \\
\hline Cor_a_e & & & & $\mathrm{hh}$ & $\mathrm{hhhh}$ & hhhh \\
\hline 2ALG_SS & & & & $\mathrm{hh}$ & hhhhhhhhhh & hhhh \\
\hline Cor_a_e & 49 & PSCCKGVRAV & NDASRTTSDR & QSACNCLKDT & AKGIAGLNPN & LAMGLPGKCG \\
\hline $2 \mathrm{ALG}$ & 25 & pacengirnv & nnlarttpdr & qaacnc $1 \mathrm{kq} 1$ & sasvpgvnpn & naaalpgkeg \\
\hline Cor_a_e & & hhhhhhhhhh & hhhh & hhhhhhhhhh & $\mathrm{hhh}$ & hhhhhhhhh \\
\hline 2ALG_S & & hhhhhhhhhh & hhhh & hhhhhhhhhh & $\mathrm{hhh}$ & hhhhhhhhh \\
\hline Cor_a_e & 99 & VNIPYKISPS & TNCNN & & & \\
\hline $2 \mathrm{ALG}$ & 75 & vsipykisas & tncatvk- & & & \\
\hline
\end{tabular}

\section{Cor_a_8}

Figure 3 3D structure model for Cor_a_8 protein. (A). 3D model for Cor_a_8 protein. A. Front (left) and reverse (right) faces are shown. Position of putative lipid molecules, present in the template structure, is indicated. (B). Structure alignment of Cor_a_8 protein and the crystal structure of Pru p3, non-specific lipid transfer protein from Prunus persica (PDB code: 2ALG_A; [36]). Secondary elements are indicated as in Figure 1. Position of signal peptide is also highlighted.

as multi-domain and homo-oligomeric configurations. Recently, it has been concluded, using Synchrotronbased Fourier transform infrared microspectroscopy [30], that AC treatments substantially modified the protein structure alpha-helix to beta-sheet ratio. Taking into account the structured scaffolds of Cor_a_1.04, Cor_a_8, Cor_a_9 and Cor_a_11 proteins, as deduced from bioinformatics modelling, disorganization of such structures would lead to large modifications in the arrangement of their respective structure-dependant allergenic motifs.

\section{Discussion}

The hazelnut was selected in this research study for two reasons: (1) it is well recognized that allergies to hazelnuts are tending to be of a more severe nature, causing life-threatening and unfortunately sometimes fatal reactions, and (2) it is also an edible nut with health benefits, as it is one of the best known sources for vitamin $E$, and a good source also for B1, B2 and B6 vitamins. Indeed, the hazelnut has several important health benefits in protection against diseases. Moreover, for example, vitamin E -found in a high level/amount in hazelnuts- prevents the factors which prepare the basis for cancer disease. The reason is because if cancer is already formed in the body, then the vitamin $\mathrm{E}$ contained in hazelnuts fights to defuse the harmful cells [6-14]. In addition, the patients were selected as they clearly showed clinic hazelnut allergy data (Table 1).

Our results show for the first time that HHP processing $(300 \mathrm{Mba}, 400 \mathrm{Mba}, 500 \mathrm{Mba}$ and $600 \mathrm{Mba})$ of hazelnut flour samples analyzed via western blotting analyses 


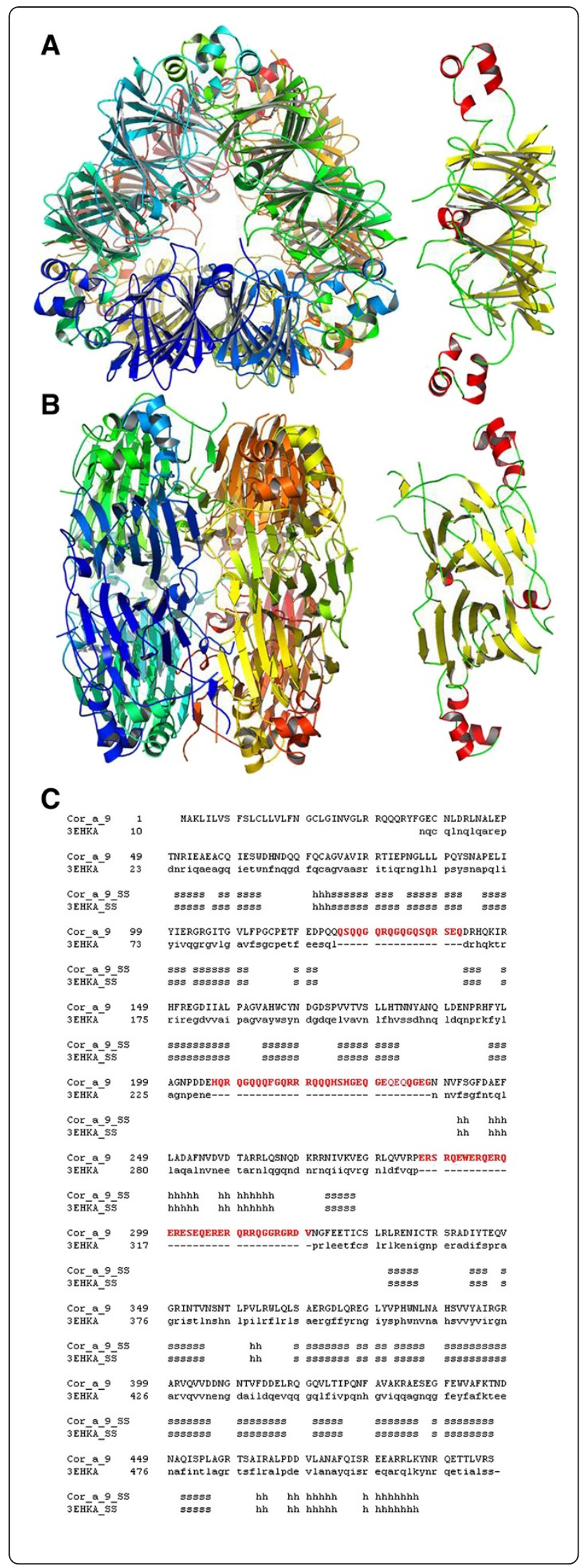

Figure 4 3D structure model for Cor_a_9 homohexameric protein. (A). 3D model for Cor_a_9 hexamer (left) and single chain (right), top view. (B). Same as A, side view. (C). Structure alignment of Cor_a_9 protein sequence and the crystal structure of Pru du amandin from Prunus dulcis (PDB code: 3EHK; [37]). Secondary elements are indicated as in Figure 1. Position of signal peptide is highlighted. Non-structured segments, absent in the template structure and therefore not modelled for Cor_a_9 sequence, are coloured in red.

did not manifest any effects on the IgE binding of Cor_a_1, Cor_a_8, Cor_a_9 and Cor_a _11 proteinallergens in the 15 studied patients (Figure $1 \mathrm{~A}, \mathrm{~B}, \mathrm{C}$ ). Also, the HHP hazelnut processed samples show a similar protein-pattern compared to the same samples without any HHP processing (raw hazelnut) via SDS-PAGE gel (Figure 6B).

A relevant point to make, is that when observing the western-blotting analyses of serum 2 (CAP $<0,35$ kilounits/L) -this serum corresponds to a patient without allergy to hazelnut- protein-bands of a molecular weight (MW) $\sim 37$ and $\sim 15 \mathrm{Kda}$ are observed (Figure $1 \mathrm{~A}$, Serum 2). We assume this is -maybe- because of crossreactivity among different edible nuts. It has been described that people with hazelnut allergies can also often suffer from reactions triggered by a number of different types of nuts, even though they do not come from closely related plant species [15-18].

At this level, one can ask: Why do some individuals show cross-reactivity to homologous proteins in tree nuts? One explanation could be that while single amino acid differences are very important in individual reactivity, the visualizations of the identified IgE binding sites via 3D, can achieve relevant biological understanding about the possible relationship among structures and sequences. Moreover, if IgE binding sequences of related proteins have similar properties, the underlying assumption is that for a group of cross-reactivity allergenic proteins, the IgE epitopes areas have similar binding affinities for the same antibodies, and have, thus, common physic chemical properties in the antibody binding sites [25-29]. Furthermore, PTM analyses (e.g. glycosylation) allow a comprehensive investigation of complete allergens. It provides clues to elucidate mechanisms of the structures that contribute to allergenicity, which thus, in turn, help alleviate food allergens [47-50], and so improve the knowledge of immunologic disorders as allergenicity processes (see Figures 2, 3, 4 and 5).

AC processing $\left(121^{\circ} \mathrm{C} 15\right.$ mins., $121^{\circ} \mathrm{C} 30$ mins., $138^{\circ} \mathrm{C}$ 15 mins., and $138^{\circ} \mathrm{C} 30$ mins.,) of hazelnut-flour samples analyzed via western blotting manifest that, the IgE binding of Cor_a_1, Cor_a_8, Cor_a_9 and Cor_a _11 proteinallergens decreases in the 15 allergic studied patients. 

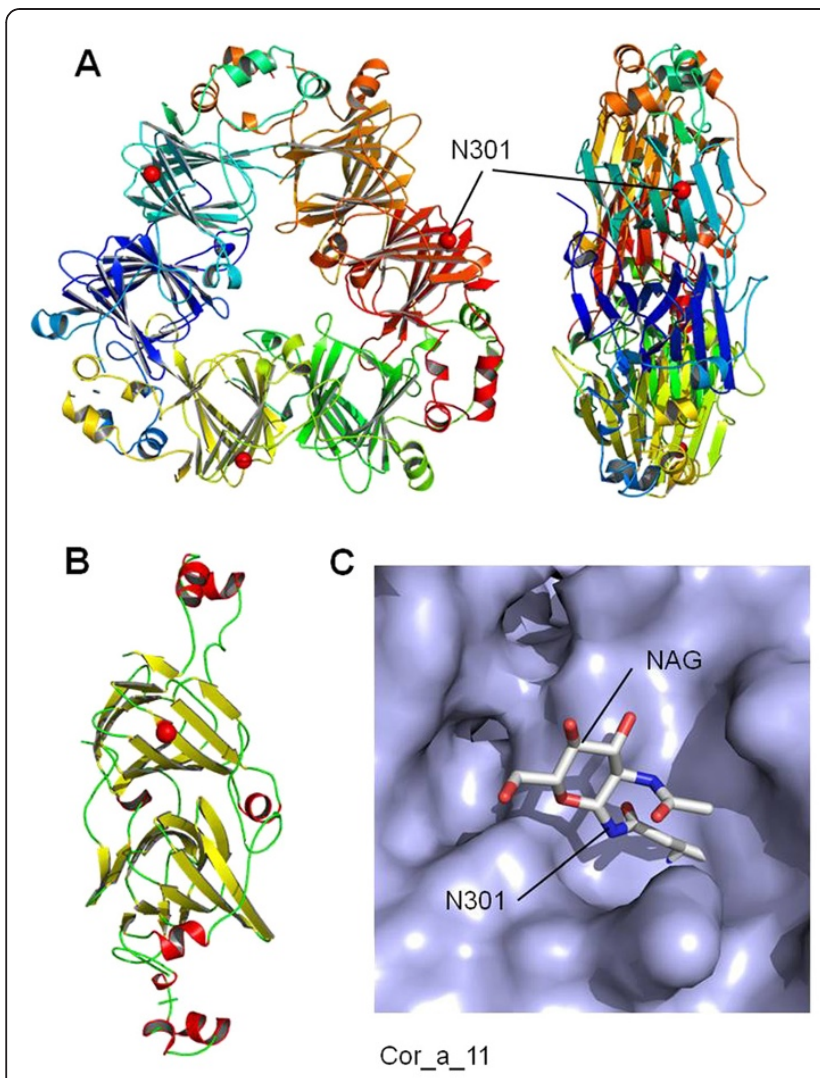

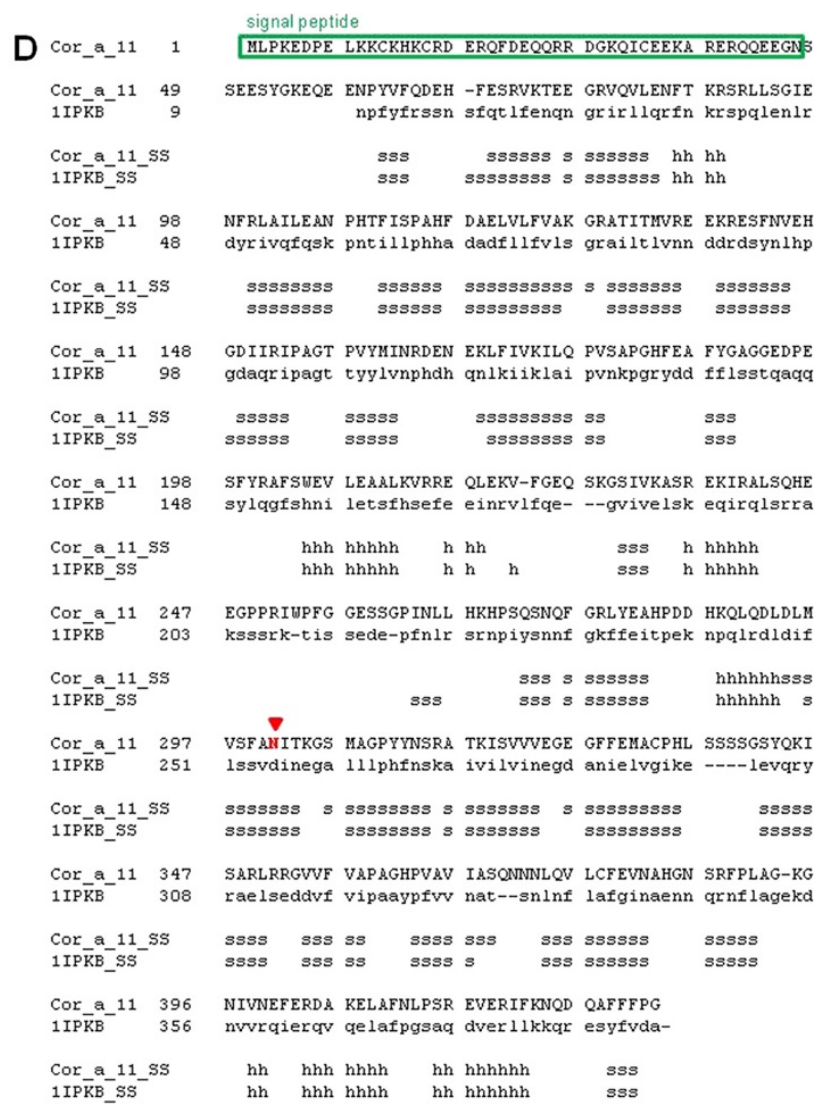

Cor_a_11

Figure 5 3D structure model for Cor_a_11 homotrimeric protein. (A). 3D model for Cor_a_11 trimer. Front (left) and side (right) faces are shown. Position of putative glycosylated Asn301 is indicated. (B). Cor_a_11 protein, single chain. (C). Putative position of glycosylated Asn301 in the surface of the protein. (D). Structure alignment of Cor_a_11 sequence and the crystal structure of soybean beta-conglycinin beta protein (PDB code: 1IPK; [38]). Positions of signal peptide and the putative glycosylated Asn301 residue are highlighted.

Indeed, immunoreactive hazelnut protein-bands disappear (Figure $1 \mathrm{~A}, \mathrm{~B}$, and $\mathrm{C}$, serum num. 3 until serum num. 17). In addition, via SDS-PAGE analysis, we could observe that the protein-patterns from the AC hazelnut-processed samples were different compared to the protein-pattern of the raw-hazelnut (without AC treatment) (Figure $6 \mathrm{~A}$ ). It would seem relevant to ask at this point: are proteinallergens from hazelnut-processed samples via AC processing aggregated? Without much doubt, yes, and probably PTMs (e.g. glycosylation) are altering the molecular structure of some hazelnut allergen-proteins when they are autoclaved [15-20,42-51]. Thus, AC processing of hazelnut seems to be affecting the 3D-structure of its allergenproteins. Perhaps due to the AC-processing, it might possible that Ag-Ab-interactions are modified, as hazelnut IgE mediated allergy is triggered by the proteins which resist processes such as cooking -for example [52-59].

In the four modelled antigen proteins, with the exception of the all-alpha Cor_a_8 protein, 3D structure can be classified as a mixed alpha + beta scaffolding, including also a variable percentage of non-structured loops connecting the secondary structure elements. From the point of view of antigenic properties, epitopes can be divided in linear and structural ones, corresponding mainly to sequence regions folded into well defined 3D structure (alpha and beta chains) or into mainly unstructured loops. As has been demonstrated previously [30], AC treatments modified the alpha to beta ratio, thus affecting mainly the 3D epitopes, and to a lesser extent to linear epitopes potentially located among them. Structure models for Cor_a_1.04 proteins (Figure 2) showed that most of the protein sequence is struct ured, the loops being located almost exclusively as the apical structures of beta-turns, and so very influenced by the beta structure itself. In this case, AC treatments are expected to be very effective, as mainly all epitopes are predicted to be structuredependant. 


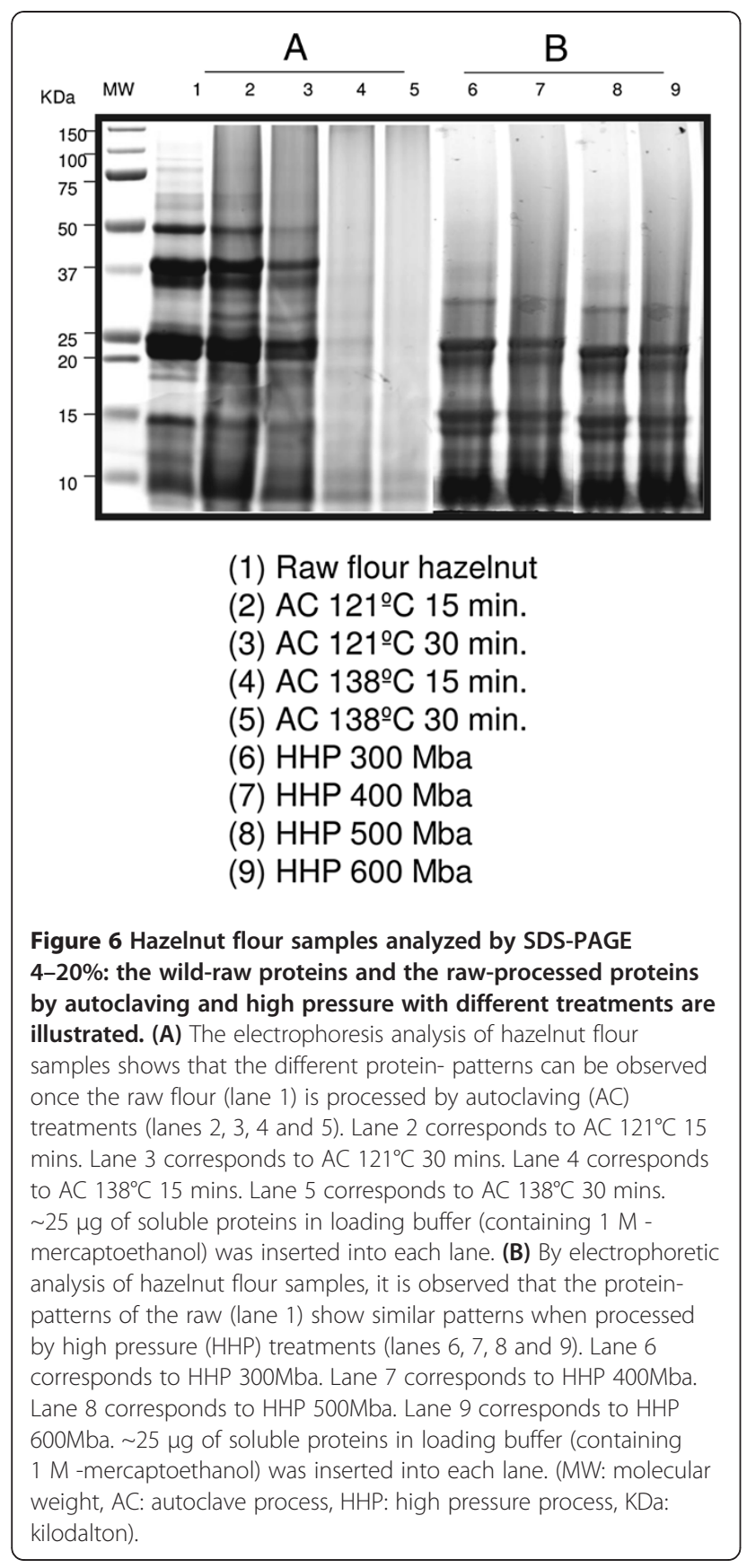

The model for the soluble domain of Cor_a_8 protein (Figure 3) exhibited a very similar arrangement, the small-size loops being located exclusively as linkers between alpha helices. Equally as for Cor_a_1.04 proteins, AC treatment for Cor_a_8 is predicted to disorganize almost all possible epitopes. The large and complex model for Cor_a_9 antigen (Figure 4), is, in contrast, predicted to be composed not only of a very structured, beta-sheet enriched, protein core, but also of long unstructured loops. These loops (red sequences in Figure 4C) cannot be modelled due precisely to their lack of stable structure, but they are predicted to carry linear epitopes, as they are located in the external faces of the protein hexamer and thus exposed to the solvent.

Nevertheless, no band of a compatible size was detected after lengthy AC treatments (Figures 1 and 6), probably indicating that the predominant antigenicity was due to structural and not linear epitopes. Finally, model for Cor_a_11 protein (Figure 5) indicated that this protein contains a low proportion of unstructured loops, being enriched in beta-sheet structures. According to this fact, AC treatment resulted in the lack of antigenicity. The model of Cor_a_11 also predicted a suitable structure arrangement for a NAG group attached to Asn 301 residue, as the initial site for glycosylation of the protein. Position of Asn 301 in a structured beta sheet makes this position a candidate for structural changes after $\mathrm{AC}$ treatment and thus to a putative loss of antigenicity due to the presence of sugar moiety. In addition, in vivo assays with the AC-processed hazelnut samples (for example via Prick- Prick) will be performed in the future, in order to verify if specific immunoreactions, mediated by IgE, decrease in those patients diagnosed with allergy to hazelnuts $[60,61]$.

\section{Conclusions}

An important reduction in allergenicity in vitro to hazelnut flour after AC processing was observed in the allergic clinic patients studied via western blotting analyses, while no reduction in allergenicity after HHP processing was observed.

Allergenicity processes are in a great manner dependent on the molecular recognition of specific structure motifs of proteins and their variation could be a putative explanation for the effects of AC processing on the allergenicity of the immunoreactive hazelnut protein-bands. Thus, a series of homologybased bioinformatics 3D models were generated. The visualization of a relevant glycosylation for the first time in the protein-allergen Cor-a-11 structure was observed, showing a new role which could open a new door for allergenicity- unravellings according to the data presented in this article.

A high number of technique-combinationapproaches are available for clinical allergy research. It is always necessary to test different strategies in order to reach a greater level of efficiency for your clinical study according to the type of samples to be analyzed. We aimed to detail the current and useful techniques to carry out in vitro allergenic studies which may be helpful for understanding hazelnut allergy, IgE mediated. This study is also aimed at combining functional research protein-allergen analysis with structural analysis of allergenic proteins, in 
order to visualize putative PTMs as glycosylation, which can help to unravel biological understanding with clinical significance. Nowadays it is essential that clinicians and scientific experts work together in order to improve the therapies and diagnosis advances for hazelnut allergy disease.

\section{Competing interests}

The authors declare that they have no competing interests.

\section{Authors' contributions}

EL carried out the immunoblotting analyses with human sera, and structural and modelling studies of hazelnut proteins Cor_a_1.04, Cor_a_8, Cor_a_9 and Cor a 11 (Centro de Investigación (i + 12) del Hospital Universitario 12 de Octubre, Avda de Córdoba s/n 28041, Madrid, Spain). CC and CB provided the AC and HHP processing samples and the SDS PAGE gel (Departamento de Tecnología de Alimentos, SGIT-INIA, Ctra. La Coruña Km 7.5, 28040 Madrid, Spain). MAJ, JR and JFC provided the patient sera (Hospital Universitario 12 de Octubre, Servicio de Alergia, and Centro de Investigación (i + 12) Av. de Córdoba s/n 28040, Madrid, Spain). All authors revised it critically for intellectual content and publish this article. All authors read and approved the final manuscript.

\section{Acknowledgements}

EL and this Scientific Research study have been supported by "AGL200803453-C02-01 del Programa Nacional de Proyectos de Investigación Fundamental-Marco VI Plan de Investigación Científica, Desarrollo e Innovación Tecnológica" del Hospital Universitario 12 de Octubre. Special thanks Prof. Paulino Gómez-Puertas (Research Centre Severo Ochoa, CBM Madrid) and Biomol Team (Parque Científico de Madrid) who contributed to the publication of this article. Special thanks also for Clinical and Translational Medicine support (www.clintransmed.com) and International Molecular Sciences IJMS

\section{Author details}

Centro de Investigación (i + 12) del Hospital Universitario 12 de Octubre Avda de Córdoba, s/n, 28041, Madrid, Spain. ${ }^{2}$ Departamento de Tecnología de Alimentos, SGIT-INIA, Ctra. La Coruña Km 7.5, 28040, Madrid, Spain. ${ }^{3}$ Servicio de Alergia del Hospital Universitario 12 de Octubre, Av. de Córdoba s/n, 28040, Madrid, Spain.

Received: 1 February 2012 Accepted: 8 May 2012

Published: 22 May 2012

\section{References}

1. Schocker F, Lüttkopf D, Scheurer S, Petersen A, Cisteró-Bahima A, Enrique E, San Miguel-Moncín M, Akkerdaas J, van Ree R, Vieths S, Becker WM: Recombinant lipid transfer protein Cor a 8 from hazelnut: a new tool for in vitro diagnosis of potentially severe hazelnut allergy. J Allergy Clin Immunol 2004, 113(1):141-147.

2. Beyer K, Grishina G, Bardina L, Grishin A, Sampson HA: Identification of an $11 \mathrm{~S}$ globulin as a major hazelnut food allergen in hazelnut-induced systemic reactions. J Allergy Clin Immunol 2002, 110(3):517-523.

3. Wensing M, Penninks AH, Hefle SL, Akkerdaas JH, van Ree R, Koppelman SJ, Bruijnzeel-Koomen CA, Knulst AC: The range of minimum provoking doses in hazelnut- allergic patients as determined by double-blind, placebocontrolled food challenges. Clin Exp Allergy 2002, 32(12):1757-1762.

4. Ortolani C, Ballmer-Weber BK, Hansen KS, Ispano M, Wüthrich B, BindslevJensen C, Ansaloni R, Vannucci L, Pravettoni V, Scibilia J, Poulsen LK, Pastorello EA: Hazelnut allergy: a double-blind, placebo-controlled food challenge multicenter study. J Allergy Clin Immunol 2000, 105(3):577-581.

5. Pumphrey RS, Stanworth SJ: The clinical spectrum of anaphylaxis in north-west England. Clin Exp Allergy 1996, 26(12):1364-1370.

6. Kagan RS, Joseph L, Dufresne C, Gray-Donald K, Turnbull E, Pierre YS, Clarke AE: Prevalence of peanut allergy in primary-school children in Montreal Canada. J Allergy Clin Immunol 2003, 112(6):1223-1228.

7. Brix S, Bovetto L, Fritsché R, Barkholt V, Frøkiaer H: Immunostimulatory potential of beta-lactoglobulin preparations: effects caused by endotoxin contamination. J Allergy Clin Immunol 2003, 112(6):1216-1222.
8. National Toxicology Program: NTP Toxicology and Carcinogenesis Studies of Methylphenidate Hydrochloride (CAS No. 298-59-9) in F344/N Rats and B6C3F1 Mice (Feed Studies). Natl Toxicol Program Tech Rep Ser 1995, 439:1-299.

9. Schmid-Grendelmeier P: Recombinant allergens. For routine use or still only science? Hautarzt 2010, 61(11):946-953. German.

10. van Hoffen E, Peeters KA, van Neerven RJ, van der Tas CW, Zuidmeer $L$, van leperen-van Dijk AG, Bruijnzeel-Koomen CA, Knol EF, van Ree R, Knulst AC: Effect of birchpollen-specific immunotherapy on birch pollen-related hazelnut allergy. J AllergyClin Immunol 2011, 127(1):100-101. e1-3.

11. Rebe Raz S, Liu H, Norde W, Bremer MG: Food allergens profiling with an imaging surface plasmon resonance-based biosensor. Anal Chem 2010, 82(20):8485-8491.

12. Röder M, Baltruweit I, Gruyters H, Ibach A, Mücke I, Matissek R, Vieths S, Holzhauser T: Allergen sanitation in the food industry: a systematic industrial scale approach toreduce hazelnut cross-contamination of cookies. J Food Prot 2010, 73(9):1671-1679.

13. Hartz C, Lauer I, del Mar San Miguel Moncin M, Cistero-Bahima A, Foetisch K, Lidholm J, Vieths S, Scheurer S: Comparison of IgE-binding capacity, cross-reactivity and biological potency of allergenic non-specific lipid transfer proteins from peach, cherry and hazelnut. Int Arch Allergy Immunol 2010, 153(4):335-346.

14. Guillamón E, Burbano C, Cuadrado C, Muzquiz M, Pedrosa MM, Sánchez M Cabanillas B, Crespo JF, Rodriguez J, Haddad J, Allaf K: Effect of an instantaneous controlled pressure drop on in vitro allergenicity to lupins (Lupinus albus var Multolupa). Int Arch Allergy Immunol 2008, 145(1):9-14.

15. Calhoun KH, Schofield ML: IgE-mediated food allergy. Curr Opin Otolaryngol Head Neck Surg 2010, 18(3):182-186.

16. Campbell AK, Matthews SB, Vassel N, Cox CD, Naseem R, Chaichi J, Holland IB, Green J, Wann KT: Bacterial metabolic 'toxins': a new mechanism for lactose and food intolerance, and irritable bowel syndrome. Toxicology 2010, 278(3):268-276.

17. Genuis SJ: Sensitivity-related illness: the escalating pandemic of allergy, food intolerance and chemical sensitivity. Sci Total Environ 2010, 408 (24):6047-6061.

18. Xiang P, Haas EJ, Zeece MG, Markwell J, Sarath G: C-Terminal 23 kDa polypeptide of soybean Gly $\mathrm{m} \mathrm{Bd} 28 \mathrm{~K}$ is a potential allergen. Planta 2004, 220(1):56-63.

19. Fæste CK, Rønning HT, Christians U, Granum PE: Liquid chromatography and mass spectrometry in food allergen detection. J Food Prot 2011, 74(2):316-345.

20. Sancho Al, Mills EN: Proteomic approaches for qualitative and quantitative characterisation of food allergens. Regul Toxicol Pharmacol 2010, 58(3Suppl):S42-S46.

21. Hansen KS, Ballmer-Weber BK, Lüttkopf D, Skov PS, Wüthrich B, BindslevJensen C, Vieths S, Poulsen LK: Roasted hazelnuts-allergenic activity evaluated by double-blind, placebo-controlled food challenge. Allergy 2003, 58(2):132-138.

22. Ortolani C, Ballmer-Weber BK, Hansen KS, Ispano M, Wüthrich B, BindslevJensen C, Ansaloni R, Vannucci L, Pravettoni V, Scibilia J, Poulsen LK, Pastorello EA: Hazelnut allergy: a double-blind, placebo-controlled food challenge multicenter study. J Allergy Clin Immunol 2000, 105(3):577-581.

23. Dupont D, Mandalari G, Mollé D, Jardin J, Rolet-Répécaud O, Duboz G, Léonil J, Mills CE, Mackie AR: Food processing increases casein resistance to simulated infant digestion. Mol Nutr Food Res 2010, 54(11):1677-1689.

24. Oezguen N, Zhou B, Negi SS, Ivanciuc O, Schein CH, Labesse G, Braun W: Comprehensive 3D-modeling of allergenic proteins and amino acid composition of potential conformational IgE epitopes. Mol Immunol 2008, 45:3740-3747

25. Marti P, Truffer R, Stadler MB, Keller-Gautschi E, Crameri R, Mari A, SchmidGrendelmeier P, Miescher SM, Stadler BM, Vogel M: Allergen motifs and the prediction of allergenicity. Immunol Lett 2007, 109:47-55.

26. Ivanciuc O, Schein CH, Garcia T, Oezguen N, Negi SS, Braun W: Structural analysis of linear and conformational epitopes of allergens. Regul Toxicol Pharmacol 2009, 54(3 Suppl):S11-S19.

27. Tey SL, Brown R, Chisholm A, Gray A, Williams S, Delahunty C: Current guidelines for nut consumption are achievable and sustainable: a hazelnut intervention. Br J Nutr 2011, 105(10):1503-1511.

28. Ozilgen M, Ozdemir M: A review on grain and nut deterioration and design of the dryers for safe storage with special reference to Turkish hazelnuts. Crit Rev Food Sci Nutr 2001, 41(2):95-132.

29. Alasalvar C, Amaral JS, Shahidi F: Functional lipid characteristics of Turkish 
Tombul hazelnut (Corylus avellana L.). J Agric Food Chem 2006, 54 (26):10177-10183.

30. Doiron K, Yu P, McKinnon JJ, Christensen DA: Heat-induced protein structure and subfractions in relation to protein degradation kinetics and intestinal availability in dairy cattle. J Dairy Sci 2009, 92:3319-3330

31. Fling SP, Gregerson DS: Peptide and protein molecular weight determination by electrophoresis using a high-molarity tris buffer system without urea. Anal Biochem 1986, 155(1):83-88.

32. Towbin H, Staehelin T, Gordon J: Electrophoretic transfer of proteins from polyacrylamide gels to nitrocellulose sheets: procedure and some applications. Proc Natl Acad Sci USA 1979, 76:4350-4354.

33. Nadal P, Canela N, Katakis I, O'Sullivan CK: Extraction, isolation, and characterization of globulin proteins from Lupinus albus. J Agric Food Chem 2011, 59(6):2752-2758.

34. Williams LW: Skin testing and food challenges for the evaluation of food allergy. Curr Allergy Rep 2001, 1(1):61-66.

35. De Boer R, Fitzsimons R, Brathwaite N: Eight myths from the food allergy clinic. Curr Allergy Clin Immunol 2009, 22:104-107.

36. Nowak-Wegrzyn A, Assa'ad AH, Bahna SL, et al: Work group report: oral food challenge testing. J Allergy Clin Immunol 2009, 123:S365-S383.

37. Zaborsky N, Brunner M, Wallner M, Himly M, Karl T, Schwarzenbacher R, Ferreira F, Achatz G: Antigen aggregation decides the fate of the allergic immune response. J Immunol 2010, 184:725-735.

38. Pasquato N, Berni R, Folli C, Folloni S, Cianci M, Pantano S, Helliwell JR, Zanotti G: Crystal structure of peach Pru p 3, the prototypic member of the family of plant non- specific lipid transfer protein pan-allergens. J Mol Biol 2006, 356:684-694.

39. Gaur V, Sethi DK, Salunkea DM: Purification, identification and preliminary crystallographic studies of Pru du amandin, an allergenic protein from Prunus dulcis. Acta Crystallogr Sect F Struct Biol Cryst Commun 2008, 64:32-35.

40. Maruyama N, Adachi M, Takahashi K, Yagasaki K, Kohno M, Takenaka Y, Okuda E, Nakagawa S, Mikami B, Utsumi S: Crystal structures of recombinant and native soybean beta-conglycinin beta homotrimers. Eur J Biochem 2001, 268:3595-3604

41. Lauer I, Foetisch K, Kolarich D, Ballmer-Weber BK, Conti A, Altmann F, Vieths S, Scheurer S: Hazelnut (Corylus avellana) vicilin Cor a 11: molecular characterization of a glycoprotein and its allergenic activity. Biochem J 2004, 383:327-334

42. Guex N, Diemand A, Peitsch MC: Protein modelling for all. Trends Biochem Sci 1999, 24:364-367.

43. Peitsch MC: ProMod and Swiss-Model: Internet-based tools for automated comparative protein modelling. Biochem Soc Trans 1996, 24:274-279.

44. Schwede T, Kopp J, Guex N, Peitsch MC: SWISS-MODEL: An automated protein homology-modeling server. Nucleic Acids Res 2003, 31:3381-3385

45. Benkert P, Biasini $\mathrm{M}$, Schwede T: Toward the estimation of the absolute quality of individual protein structure models. Bioinformatics 2011, 27:343-350.

46. Guex N, Peitsch MC: SWISS-MODEL and the Swiss-PdbViewer: an environment for comparative protein modeling. Electrophoresis 1997, $18: 2714-2723$

47. Mann M, Jensen ON: Proteomic analysis of post-translational modifications. Nat Biotechnol 2003, 21(3):255-261.

48. López E, Matthiesen R, López I, Ashman K, Mendieta J, Wesselink JJ, GómezPuertas $P$, Ferreira A: Functional phosphoproteomics for current immunology research. J Integr OMICS 2011, 1(1):1-16. doi:10.5584/jiomics. v1i1.40. http://www.jiomics.com/index.php/jio/article/view/40.

49. López E, López I, Ferreira A, Sequí J: Clinical and technical phosphoproteomic research. Proteome Sci 2011, 9:27.

50. Bestoso F, Ottaggio L, Armirotti A, Balbi A, Damonte G, Degan P, Mazzei M, Cavalli F, Ledda B, Miele M: In vitro cell cultures obtained from different explants of Corylus avellana produce Taxol and taxanes. BMC Biotechnol 2006, 6:45

51. Bergeron JJ, Zapun A, Ou WJ, Hemming R, Parlati F, Cameron PH, Thomas DY: The role of the lectin calnexin in conformation independent binding to N-linked glycoproteins and quality control. Adv Exp Med Biol 1998, 435:105-116.

52. Trombetta ES, Helenius A: Lectins as chaperones in glycoprotein folding. Curr Opin Struct Biol 1998, 8(5):587-592.

53. Ghendler Y, Smolyar A, Chang HC, Reinherz EL: One of the CD3epsilon subunits within a $T$ cell receptor complex lies in close proximity to the Cbeta FG loop. J Exp Med 1998, 187(9):1529-1536.
54. Jones EY, Davis SJ, Williams AF, Harlos K, Stuart DI: Crystal structure at 2.8 A resolution of a soluble form of the cell adhesion molecule CD2. Nature 1992, 360(6401):232-239

55. Rudd PM, Wormald MR, Harvey DJ, Devasahayam M, McAlister MS, Brown MH, Davis SJ, Barclay AN, Dwek RA: Oligosaccharide analysis and molecular modeling of soluble forms of glycoproteins belonging to the Ly-6, scavenger receptor, and immunoglobulin superfamilies expressed in Chinese hamster ovary cells. Glycobiology 1999, 5:443-458.

56. Weis WI, Drickamer K, Hendrickson WA: Structure of a C-type mannosebinding protein complexed with an oligosaccharide. Nature 1992, 360 (6400):127-134.

57. Fletcher CM, Harrison RA, Lachmann PJ, Neuhaus D: Structure of a soluble, glycosylated form of the human complement regulatory protein CD59. Structure 1994, 2(3):185-199.

58. Palmisano G, Lendal SE, Larsen MR: Titanium dioxide enrichment of sialic acid- containing glycopeptides. Methods Mol Biol 2011, 753:309-322.

59. Yano H: Disulfide-related proteomic studies on food allergens. Expert Rev Proteomics 2009, 5:563-571

60. Radauer C, Bublin M, Wagner S, Mari A, Breiteneder H: Allergens are distributed into few protein families and possess a restricted number of biochemical functions. J Allergy Clin Immunol 2008, 121(4):847-852. e7.

61. López E, Wesselink JJ, López I, Mendieta J, Gómez-Puertas P, Muñoz SR: Technical phosphoproteomic and bioinformatic tools useful in cancer research. J Clin Bioinforma 2011, 1:26.

doi:10.1186/2043-9113-2-12

Cite this article as: López et al:: Effects of autoclaving and high pressure on allergenicity of hazelnut proteins. Journal of Clinical Bioinformatics 2012 2:12.

\section{Submit your next manuscript to BioMed Central and take full advantage of:}

- Convenient online submission

- Thorough peer review

- No space constraints or color figure charges

- Immediate publication on acceptance

- Inclusion in PubMed, CAS, Scopus and Google Scholar

- Research which is freely available for redistribution 